\title{
Monitoring tools of regional economic security
}

\author{
$E A$ Husainova*, $L R$ Urazbahtina, $N A$ Serkina, $E A$ Dolonina and $O V$ Filina
}

Kazan State Energy University, 420066, Kazan, st. Krasnoselskaya, 51, Russian Federation

\begin{abstract}
Ensuring the economic security of the region is one of the key tasks of the management of the federal entity. By ensuring economic security, the priorities of the management of the region are determined, so that the system of economic security should be integrated into the development management system of the socio-economic system of the region and perform an information and analytical function in it, which requires the development and introduction of economic security monitoring tools into the regional development management system. The article formulated an algorithm integration tools for monitoring threats to economic security in the regional economic development of the control system the methodical approach to assessing threats to regional economic security.
\end{abstract}

\section{Introduction}

Ensuring the economic security of the region is one of the key tasks of the management of the federal entity. By ensuring economic security, the priorities of the management of the region are determined, so that the system of economic security should be integrated into the development management system of the socioeconomic system of the region and perform an information and analytical function in it, which requires the development and introduction of economic security monitoring tools into the regional development management system [1].

\section{Monitoring tools of regional economic security}

The regional economy is an open dynamic hierarchical system, whose subjects are characterized by a common territorial location, proximity of economic, social, cultural, historical and other conditions of existence. The economic development of the region is a continuous process of dynamic transformation of relations involving economic agents and their assets. The economic security of the region is seen as an endogenous factor of regional development, the ability of the region as a system to achieve targets with efficient use of resources, as well as to maintain its inherent attribution characteristics in conditions of instability and uncertainty of the external and internal environment, that is, the presence of some threats and risks.

The threat is defined as a real objective possibility of destructive changes in the essential characteristics of assets and economic agents, as well as the state of relations between them, due to changes in the parameters of the external environment. Risk is treated as a potential choice on the part of an economic agent characterized by alternative, uncertainty, probability.

Monitoring and forecasting threats to economic security is a necessary element of the regional development management system, as it identifies qualitative changes in the composition and content of the properties of the entities and facilities of the regional economic system in the process of systematic monitoring. Monitoring threats to economic security results in the analysis and diagnosis of the level of security of the regional economic system and its individual components in order to adjust the control measures, determine quantitative indicators of potential risks and ensure the achievement of regional development targets [2].

In order to integrate the tools for monitoring economic security threats into the regional development management system on the basis of taking into account the risk factor and objectivity of its assessment, an algorithm has been developed, the characteristic of which is the correlation of its stages with the stages of development of the social and economic development strategy of the region and the need for continuous monitoring of economic security threats and risk indicators [3].

Based on the developed strategic matrix of regional economic development of the Republic of Tatarstan, the regional potential and impact of regional risk-forming factors on stable economic development were studied, influence risks were typologized and the combined risks of economic development of the region were decomposed and specified [4].

The risk decomposition was based on the ranking of risks from those having a stronger impact to those having less impact. The expert assessment presented in table 1 contributes to the distribution of risks by their impact levels and types based on the risk impact scale developed. Risk distribution by risk probability matrix

\footnotetext{
*orresponding author: Ekaterina0686@yahoo.com
} 
Table 1. Estimation of the probability of occurrence of risk on the proposed scale of risk gradation.

\begin{tabular}{|c|c|}
\hline $\begin{array}{c}\text { Expert assessment of the probability of } \\
\text { occurrence of risk }\end{array}$ & The average probability of the range \\
\hline Extremely risky situation & $(0.81-1.0) 0.895$ \\
\hline High risk situation & $(0.62-0.8) 0.71$ \\
\hline Average risk & $(0,42-0,61) 0,505$ \\
\hline Low risk & $(0.21-0.41) 0.31$ \\
\hline Very low risk & $(0,01-0,2) 0,095$ \\
\hline There is no risk & 0 \\
\hline
\end{tabular}

Table 2. R MC card for ranked risks.

\begin{tabular}{|c|c|c|c|c|c|c|c|}
\hline \multirow{2}{*}{$\begin{array}{c}\text { Risk } \\
\text { probability }\end{array}$} & \multicolumn{7}{|c|}{ Risk averaged measure } \\
\cline { 2 - 8 } & Very low & Low & $\begin{array}{c}\text { Below the } \\
\text { average }\end{array}$ & Average & $\begin{array}{c}\text { Above the } \\
\text { average }\end{array}$ & High & Very high \\
\cline { 2 - 8 } & 0.05 & 0.1 & 0.3 & 0.5 & 0.7 & 0.9 & 0.95 \\
\hline 0.895 & 0.0448 & 0.0895 & 0.2685 & 0,4475 & 0.6265 & 0.8055 & 0.8503 \\
\hline 0.71 & 0.0355 & 0.071 & 0,213 & 0.355 & 0.497 & 0.639 & 0.6745 \\
\hline 0,505 & 0.0253 & 0.0505 & 0.1515 & 0.2525 & 0.3535 & 0.4545 & 0.4798 \\
\hline 0.31 & 0,0155 & 0.031 & 0.093 & 0.155 & 0,217 & 0.279 & 0.2945 \\
\hline 0.095 & 0,0048 & 0,0095 & 0.0285 & 0.0475 & 0.0665 & 0.0855 & 0.0903 \\
\hline
\end{tabular}

and their influence allows to rank probability and degree of influence of investigated risks, i.e. to calculate their ranks as a product of probability of risk occurrence on degree of its influence. Based on expert assessments, an RMC card [risk-managementcard] for typologized risk ranks has been compiled according to this scale (Table 2).

As a result of the construction of the RMC-map, zones are visualized, according to which the direction of the management solution is determined [4]:

- in case of minor risk (left lower segment of matrix, light grey range) management solution can be positive and without changes in target setting, that is, alternative solutions are not required;

- a significant level of risk (upper right corner of the matrix, darkest zone) requires modification for purposes conducive to risk elimination;

- the average level of risk impact (the middle zone adjacent to the dark net) results in changes in management decisions that help minimize the risk, that is, reduce the probability of its occurrence, and require the development of alternative solutions;

- "below average" risk level (white zone) requires investigation of additional conditions and collection of additional information in order to accept or not accept the risk.

Based on the results of risk specification and ranking by influence levels, it should be noted that there is currently no high and very high impact risk field in the Republic of Tatarstan, which is due to the sufficiently stable regional socio-economic situation of the Republic, but the presence of risks of the level of influence "above average" makes it necessary to develop management decisions to reduce the impact of these risks on the economic development of the Republic of Tatarstan [5].

However, the analysis of the aggregate assessment of risks of economic development of the Republic of Tatarstan when comparing them with the data of the RMC-map built by us for the ranks of typologized risks, allowed to identify risks subject to reduction as a result of management decisions, which is presented in Table 3 . The analysis showed that the direct assessment of risk is not an objective category, and generally the impact of a combination of private risks is an average, while further analysis of the obtained risk ranks, both private and aggregate, using the RMC map, allows to specify the risks requiring the development and implementation of management measures by regional authorities [6]. 
Table 3. The result of the comparison of the obtained risk assessment with the RMC card data.

\begin{tabular}{|c|c|c|c|}
\hline Risk identification & Risk name & Rank risk & RMC card area \\
\hline \multicolumn{2}{|c|}{$\begin{array}{c}\text { Set of environmental risks } \\
\end{array}$} & 0.2998 & medium gray zone \\
\hline $1 \mathrm{C}$ & reduction of labor costs & 0.08265 & white zone \\
\hline $2 \mathrm{C}$ & job cuts & 0.084075 & white zone \\
\hline $3 \mathrm{C}$ & rising unemployment & 0.083244 & white zone \\
\hline $4 \mathrm{C}$ & decrease in cash incomes & 0.084313 & white zone \\
\hline $5 \mathrm{C}$ & $\begin{array}{l}\text { increase in the tax burden on the } \\
\text { population }\end{array}$ & 0.077969 & white zone \\
\hline $6 \mathrm{C}$ & reduction in social payments & 0.078125 & white zone \\
\hline \multicolumn{2}{|c|}{ Set of social risks } & 0.550572 & dark gray zone \\
\hline 1 and & $\begin{array}{l}\text { reduced competitiveness of } \\
\text { regional products }\end{array}$ & 0.285023 & white zone \\
\hline \multicolumn{2}{|c|}{ Set of investment risks } & 0.41351 & medium gray zone \\
\hline $1 \mathrm{~F}$ & $\begin{array}{l}\text { the unstable position of the } \\
\text { financial and banking sector }\end{array}$ & 0.411297 & medium gray zone \\
\hline $2 \mathrm{~F}$ & $\begin{array}{l}\text { increase in the turnover period of } \\
\text { fixed and circulating capital }\end{array}$ & 0.1623171 & white zone \\
\hline \multicolumn{2}{|c|}{ Set of financial risks } & 0.5829437 & dark gray zone \\
\hline \multicolumn{2}{|c|}{ Set of economic risks } & 0.527998023 & dark gray zone \\
\hline
\end{tabular}

The calculation of the probability of damage with the combined impact of risks on economic development in accordance with the developed risk impact scale shows that the possibility of causing significant damage is realized with a probability of $94.14 \%$. Thus, the need for variable management decisions to reduce the likelihood of negative impacts of the risks identified in this study is updated [8].

As a result of the construction of solution matrices for private risks planned for minimization, changes in the risk field of the Republic of Tatarstan are predicted, which has led to the need to monitor risk migration [9].

On the basis of the above, scenario forecasting of the dynamics of GRP, index of physical volume of investments in fixed assets and real monetary income of the population of the Republic of Tatarstan was carried out on the conditions of unchanged trends (inertial scenario) and economic development in the conditions of integration of tools for monitoring threats to economic security into regional management, which contributes to reduction of the risk field (modification scenario) [10].

This monitoring should be carried out regularly in order to identify the dynamics of risk migration and to make timely decisions on risk response [11].

The study led to scenario forecasting of the Republic of Tatarstan, demonstrating options for further regional economic development under conditions of unchanged trends (inertial scenario) and economic development under conditions of integration of tools for monitoring threats to economic security into regional management, which contributes to reduction of risk field (modification scenario) $[12,13]$.

The result of the forecast shows accelerated and more even regional economic development due to the implementation of the modification scenario, which indicates the expediency of integrating the tools of monitoring threats to economic security into the system of managing the economic security of the region and regional economic development [14]. The implementation of the proposed recommendations contributes to the timely and complete identification of threats to economic security and an objective assessment of regional risks, which is a prerequisite for the development of effective measures to reduce them [15].

\section{References}

1. V.M. Bautin, M.A. Shatalov, Integration of food industry enterprises and related industries on the basis of the cluster approach, Bulletin of the Voronezh State University of Engineering Technologies, 1(63), 210-216 (2015)

2. Eds. A.N. Azriliyana, Large Economic Dictionary: 26,500 terms, 7, 1472 (2007)

3. Eds. A.M. Prokhorov, Big Encyclopedic Dictionary: $A Z, 2,1452$ (2000)

4. L.P. Vasilyeva, Management of balanced development of the region: theoretical and practical aspects, Bulletin of Belgorod University of Cooperation, Economics and Law, 2(46), 258-261 (2013)

5. G.M. Golobokova, Economic stability: a tutorial, 326 (2011)

6. A.Ya. Goncharov, Methodical methods of monitoring and diagnostics of balanced regional development, Bulletin of Belgorod University of Cooperation, Economics and Law, 3(55), 324-331 (2015)

7. L.N. Khramova, Methodical foundations for the sustainable development of the construction company, dis. cand, 17 (1998)

8. B. Raizberg, Entrepreneurship and risk, 64 (2012) 
9. O.K. Tsapieva, Sustainable Development of the Region: Theoretical Foundations and Model, Problems of the Modern Economy, 2(34) (2010)

10. M. Fritz, M. Koch, Potentials for prosperity without growth: Ecological sustainability, social inclusion and the quality of life in 38 countries, Ecological Economics, 108, 191-199 (2014)

11. I.T. Shagieva, Management of regional development: the essence and the need for transformation in the context of the modernization of the national economy, Vestnik VSU. Series: economics and management, 2,127-134 (2013)

12. R.L. Nadeau, The unfinished journey of ecological economics, Ecological Economics, 109, 101-108 (2015)

13. Yu.G. Neudahina, Organizational and economic aspects of managing a region's sustainable development: based on materials from the KabardinoBalkarian Republic, abstract of a dis., 24 (2011)

14. L.D. Gudkov, Paradoxes of studying social structure in Russia, Historical and socio-educational thought, 8(2/2), 207-224 (2016)

15. E.A. Khusainova, Development of tools for monitoring regional economic security, author. dis. kand., 24 (2018) 